\title{
Inhibition of the platelet-derived growth factor receptor beta (PDGFRB) using gene silencing, crenolanib besylate, or imatinib mesylate hampers the malignant phenotype of mesothelioma cell lines
}

\author{
Ombretta Melaiu ${ }^{1,2}$, Calogerina Catalano ${ }^{3}$, Chiara De Santi ${ }^{4}$, Monica Cipollini ${ }^{2}$, Gisella \\ Figlioli $^{5}$, Lucia Pellè ${ }^{2}$, Elisa Barone ${ }^{2}$, Monica Evangelista ${ }^{6}$, Alice Guazzelli', Laura \\ Boldrini ${ }^{8}$, Elisa Sensi ${ }^{8}$, Alessandra Bonotti ${ }^{9}$, Rudy Foddis ${ }^{10}$, Alfonso Cristaudo ${ }^{10}$, \\ Luciano Mutti ${ }^{7}$, Gabriella Fontanini ${ }^{8}$, Federica Gemignani ${ }^{2}$, and Stefano Landi ${ }^{2}$ \\ ${ }^{1}$ Paediatric Haematology/Oncology Department, IRCCS, Ospedale Pediatrico Bambino Gesù, Rome, Italy \\ 2 Department of Biology, University of Pisa, Pisa, Italy \\ ${ }^{3}$ Division of molecular genetic epidemiology, German Cancer Research Center (DKFZ), Heidelberg, Germany \\ ${ }^{4}$ Department of Medicine, Education and Research Centre, Royal College of Surgeons in Ireland, Beaumont Hospital, Dublin, \\ Ireland \\ ${ }^{5}$ IFOM, the FIRC Institute of Molecular Oncology, Milan, Italy \\ ${ }^{6}$ Institute of Clinical Physiology (IFC), CNR, Pisa, Italy \\ 7 School of Environment and Life Sciences, University of Salford, Manchester, United Kingdom \\ ${ }^{8}$ Department of Surgical, Medical, Molecular Pathology and Critical Care, Division of Pathological Anatomy, University of \\ Pisa, Pisa, Italy \\ ${ }^{9}$ Preventive and Occupational Medicine, University Hospital of Pisa, Pisa, Italy \\ 10 Department of Translational Research and of new Technologies in Medicine and Surgery, University of Pisa, Pisa, Italy \\ Correspondence to: Luciano Mutti, email: Iuciano.mutti@hotmail.it
} Keywords: Malignant Pleural Mesothelioma, therapeutic targets, PDGFRB, RNA interference, drug inhibitors Received: October 08, $2016 \quad$ Accepted: January 30, 2017

Published: February 01, 2017

\section{ABSTRACT}

Malignant pleural mesothelioma (MPM) is a cancer of the pleural cavity resistant to chemotherapy. The identification of novel therapeutic targets is needed to improve its poor prognosis. Following a review of literature and a screening of specimens we found that platelet-derived growth factor receptor beta (PDGFRB) is over-expressed, but not somatically mutated, in MPM tissues. We aimed to ascertain whether PDGFRB is a MPM-cancer driver gene. The approaches employed included the use of gene silencing and the administration of small molecules, such as crenolanib and imatinib (PDGFR inhibitors) on MPM cell lines (IstMes2, Mero-14, Mero-25). Met5A cells were used as non-malignant mesothelial cell line. PDGFRB-silencing caused a decrease in the proliferation rate, and a reduced colony formation capacity, as well as an increase of the share of cells in sub- $G_{1}$ and in $G_{2}$ phase, and increased apoptotic rate of MPM cell lines. Loss of migration ability was also observed. Similar, or even further enhanced, results were obtained with crenolanib. Imatinib showed the least effective activity on the phenotype. In conclusion, our study highlights PDGFRB as target with a clear role in MPM tumorigenesis and provided a rationale to explore further the efficacy of crenolanib in MPM patients, with promising results.

\section{INTRODUCTION}

Malignant pleural mesothelioma (MPM) is a cancer of the pleural cavity with a poor prognosis and the identification of novel therapeutic targets is urgently needed. Recently, our research group investigated the expression status of 119 candidate cancer genes in MPM tissues and cell lines. Among the identified genes, one of the most interesting was PDGFRB encoding for the platelet-derived growth factor receptor beta, already 
suggested as a MPM-cancer gene by previous research groups [1,2]. PDGF is composed of homo-dimers or hetero-dimers of two polypeptide chains, denoted A and B. Two different PDGF receptors, alpha and beta, have been described $[3,4]$. The two receptor subtypes show different affinities for the dimeric PDGF isoforms. The PDGF-alpha receptor binds with high affinity all three forms (i.e. AA, AB, and BB), whereas the beta-receptor subtype only binds PDGF-BB [5,6]. It is a confirmed observation that panels of MPM cell lines express preferentially PDGF beta-chain and PDGF beta-receptor transcripts, whereas normal mesothelial cell lines do not express PDGF B-chain mRNA and little or no PDGF betareceptor mRNA [7]. In contrast, normal mesothelial cell lines were found to express PDGF alpha-receptor mRNA, which could not be detected in mesothelioma cell lines [7]. It has been suggested that the PDGF/PDGFR-beta interaction could be involved in the carcinogenesis of various tissues, including osteosarcoma [8], meningiomas, melanomas, neuroendocrine tumors, ovarian, pancreatic, gastric, lung, prostate cancers [9], and MPM [10], with both autocrine and paracrine mechanisms of growth stimulation. In agreement with this, it has been shown that PDGFRB is also associated with the aggressive behavior of several types of tumors. The $60 \%$ of colon cancer patients express high levels of this gene and the PDGFRB expression correlates with lymphatic dissemination of this cancer [11]. Steller EJ showed that PDGFRB signaling in mesenchymal-like tumor cells (as colorectal cancer cells) contributes to invasion and liver metastasis formation [12]. High PDGFRs expression correlates with advanced stage disease and poor prognosis in breast [13], liver [14], and pancreatic carcinomas [15].

Given the role of PDGFRB in cancer, a plethora of PDGF/PDGFR pathway inhibitors are available and assayed in clinical trials for leukemia, gastrointestinal stromal tumors (GIST), and glioma (https://clinicaltrials. gov/). Thus, it is of interest to explore whether MPM patients may also benefit from the use of these agents. To this end, in the present work we studied the effect of $P D G F R B$ inhibition in MPM cell lines. The approaches included the use of gene silencing and PDGFRB inhibitors. The results support PDGFRB up-regulation as a cancer-driver mechanism and suggest this receptor as a candidate therapeutic target worth to be exploited in the treatment of this disease.

\section{RESULTS}

\section{PDGFRB somatic mutation screening}

Given that previous works and our investigations highlighted that between $20-40 \%$ of MPM specimens over-express PDGFRB [2,16,17], we wondered whether
MPM tissue samples may bear somatic mutations within the PDGFRB locus. Thus, the tyrosine kinase loop domain encoded by exons $12-18$ was screened on a series of 96 MPM specimens. We found only a common polymorphism, but no somatic mutations (Table S1). Next, to further study the possible mechanism of PDGFRB over-expression in MPM, we analyzed the copy number alterations of the $P D G F R B$ genomic region in $83 \mathrm{MPM}$ patients whose data were deposited in The Genome Cancer Atlas database (TGCA, URL at http://cancergenome.nih. gov/cancersselected/Mesothelioma). Even in this case, any significant amplification was detected in correspondence of PDGFRB genomic region (data not shown for brevity).

\section{PDGFRB expression in MPM cell lines}

The expression level of $P D G F R B$ was screened on a panel of three human MPM cell lines: Mero-14, Mero-25, and IstMes2. The SV40-immortalized Met5A cell line was used as a model of non-malignant mesothelial cells. As shown in Figure 1A, all MPM cells showed up-regulated PDGFRB expression. Mero-14 cells showed the highest amount of mRNA expression level of around 70-fold compared to that of the Met5A cell line. Mero-25 cells showed an increased expression of about 30 -fold, whereas IstMes 2 cells had a 10-fold increase. All these differences were statistically significant using Met5A as reference $\left(\mathrm{P}=6 \times 10^{-3}, \mathrm{P}=0.01\right.$, and $\mathrm{P}=3 \times 10^{-3}$, respectively). Protein expression analysis gave similar results. The highest levels of PDGFRB protein was found in Mero-14 cells with an average increase of $99 \%$ when compared to Met5A cells. Mero- 25 cells showed an increase of $97 \%$, whereas the IstMes 2 cell line had an increase of $70 \%$, as shown in Figure 1B. To study further the role of PDGFRB gene, all four cell lines underwent RNA interference (RNAi). The silencing efficiency was measured at $\mathrm{mRNA}$ and protein levels. Mero-14 and IstMes 2 cells showed a reduction of PDGFRB expression of about 95\% whereas the Mero25 cell line showed a silencing efficacy of about $50 \%$. Met5A cells showed at least 70\% PDGFRB depletion at the protein level, although the quantification was difficult given the minimal PDGFRB expression before RNAi. The results are shown both at mRNA and protein levels in Figure $1 \mathrm{C}$ and D, respectively.

\section{PDGFRB silencing and cellular growth}

SRB assay was performed to evaluate the effect of PDGFRB silencing on cellular growth of MPM cell lines. Following the administration of siPDGFRB, the proliferation rate was significantly reduced for Mero$14\left(\mathrm{P}=2 \times 10^{-3}\right)$ and IstMeS2 $\left(\mathrm{P}=6.7 \times 10^{-3}\right)$ cells, when compared to cells treated with $\mathrm{C}$ - PDGFRB. This reduction was particularly evident from the third day of treatment, and further decreased on day 8 by $30 \%$ and 
$34 \%$ respectively (Figure $2 \mathrm{~A}$ ). Mero-25 did not show any reduction, whereas the depletion of $P D G F R B$ did not produce any effect on Met5A cells. In parallel with the measurement of the proliferative capabilities of cells, a colony formation assay was used to evaluate the clonogenic capacities of silenced cells. As shown in Figure 2B, PDGFRB silencing had a strong effect on abolishing clonogenicity in Mero-14 $\left(-80.1 \% ; \mathrm{P}=2.9 \times 10^{-3}\right)$ and IstMes2 $\left(-86.3 \%, \mathrm{P}=5 \times 10^{-4}\right)$, when compared to control C- PDGFRB-transfected cells. A slight reduction of
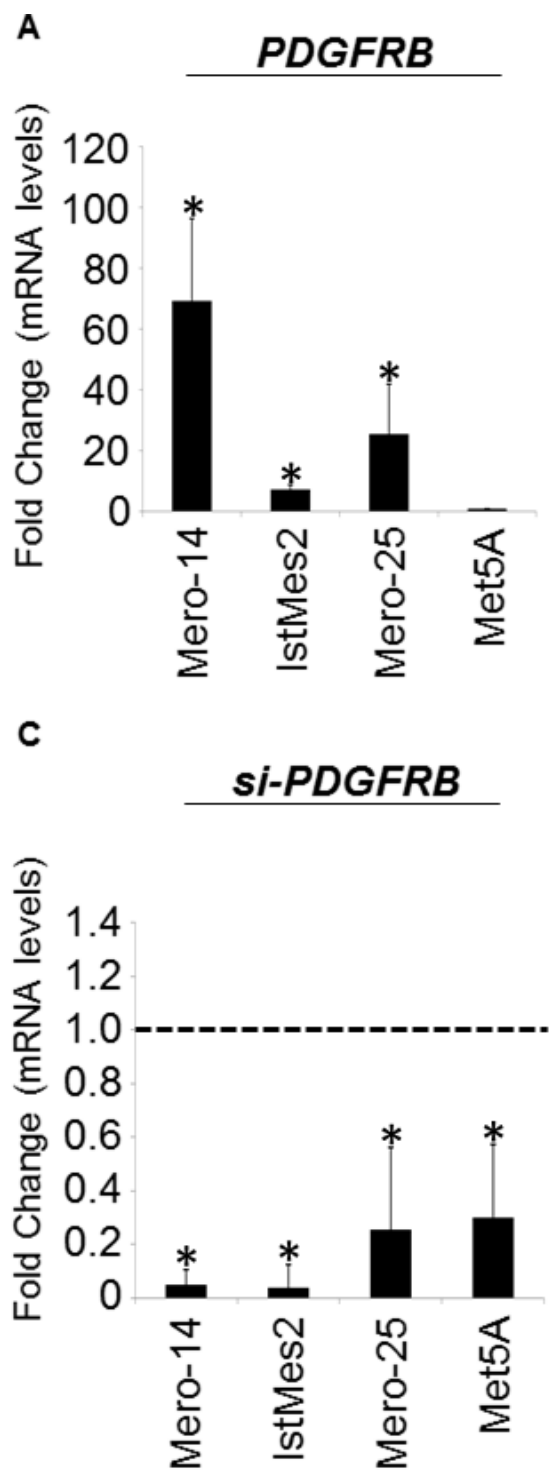

colony formation capacity was also observed in Mero-25 cells after PDGFRB silencing, but this decrease was not statistically significant (data not shown). No effect was detected on the non-MPM cells Met5A.

\section{PDGFRB silencing and cell cycle progression}

The effect of PDGFRB-silencing on the progression of cell cycle was evaluated through flow cytometry analysis. In IstMes 2 cell line, siPDGFRB induced an

\section{B}
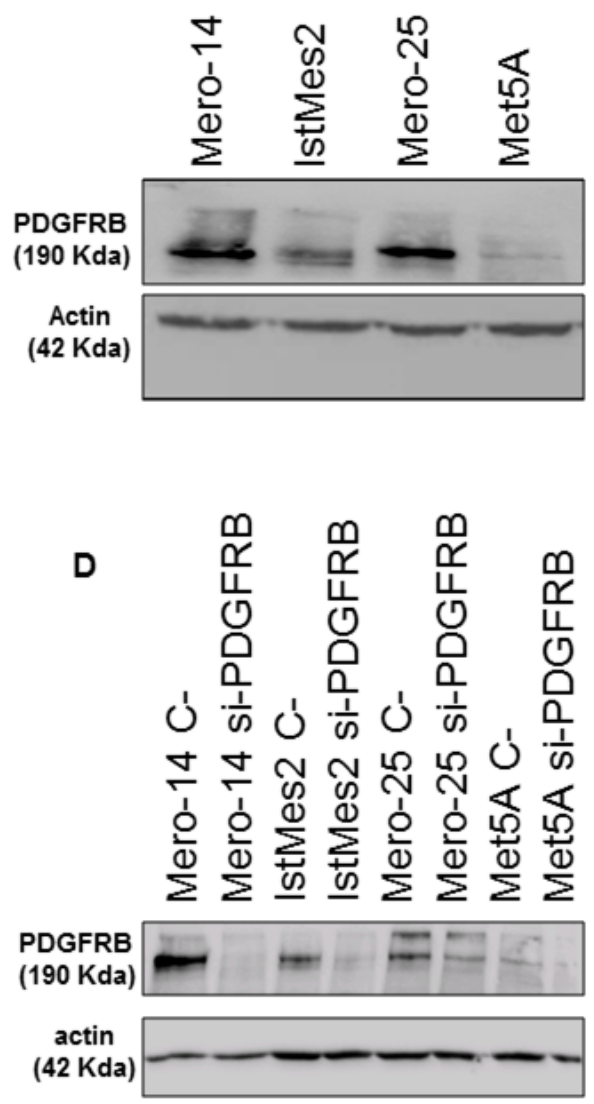

Figure 1: Expression levels of PDGFRB in Mero-14, IstMes2, and Mero-25 human MPM cell lines and Met5A. A. RT-qPCR showing the mRNA expression levels of PDGFRB measured on MPM cell lines and related to Met5A cells (set to 1). RPLP0, $H P R T$, and $T B P$ were used for normalization. Error bars show the standard error of the mean (SEM) from three independent experiments, each performed in triplicate. B. Protein levels of PDGFRB in Mero-14, IstMes2, Mero-25, and Met5A cells. $\beta$-actin was used as reference. The protein levels were confirmed by two independent experiments. C. RT-qPCR showing the mRNA expression levels of PDGFRB in Mero-14, IstMes2, Mero-25, and Met5A cells, after siPDGFRB administration, related to their own C-PDGFRB (set to 1, dotted black bar). RPLP0, HPRT, and TBP were used for normalization. Errors bars are SEM, from three independent experiments, each performed in triplicate. D. Protein levels of PDGFRB after its depletion in Mero-14, IstMes2, Mero-25, and Met5A cells. $\beta$-actin was used as reference. The protein levels were confirmed by two independent experiments. 
increase of the share of cells in sub- $\mathrm{G}_{1}(\mathrm{P}=0.03)$, a decrease of cells in $\mathrm{G}_{0} / \mathrm{G}_{1}$ phase $\left(\mathrm{P}=1.4 \times 10^{-3}\right)$, and an increase of the share of cells in $\mathrm{G}_{2} / \mathrm{M}$ checkpoint phase $\left(\mathrm{P}=10^{-3}\right)$, as compared to the same cells treated with C-PDGFRB. A similar trend, not statistically significant, was also shown for Mero-14 cells. No effects were detected on Met5A and Mero-25 cells (Table S2, A).

\section{PDGFRB silencing and apoptosis}

The activity of caspases 3 and 7 was measured for the evaluation of the apoptotic rate following PDGFRB silencing. After the transfection with siPDGFRB, Mero14 and IstMes2 cell lines showed an average increase of caspase activity of $62 \%$ and $34 \%$, respectively
(C- PDGFRB used as control $\mathrm{P}<10^{-3}$ and $\mathrm{P}=9 \times 10^{-3}$, respectively). The increase of apoptotic cells in IstMes2 was of the same order of magnitude as the increase of sub- $\mathrm{G}_{1}$ cells measured with flow cytometry. No changes were observed in Mero-25 and MeT5A cells (Figure 3A).

\section{PDGFRB silencing and migration capacity}

Wound-healing assay was employed to assess the effect of PDGFRB silencing on cellular migration of MPM cell lines. No statistically significant differences in migration were observed in Mero-25, IstMeS2, and Met5A cells following the siPDGFRB administration. Nevertheless, Mero-14 cells showed a statistically significant reduced migration ability, as compared to

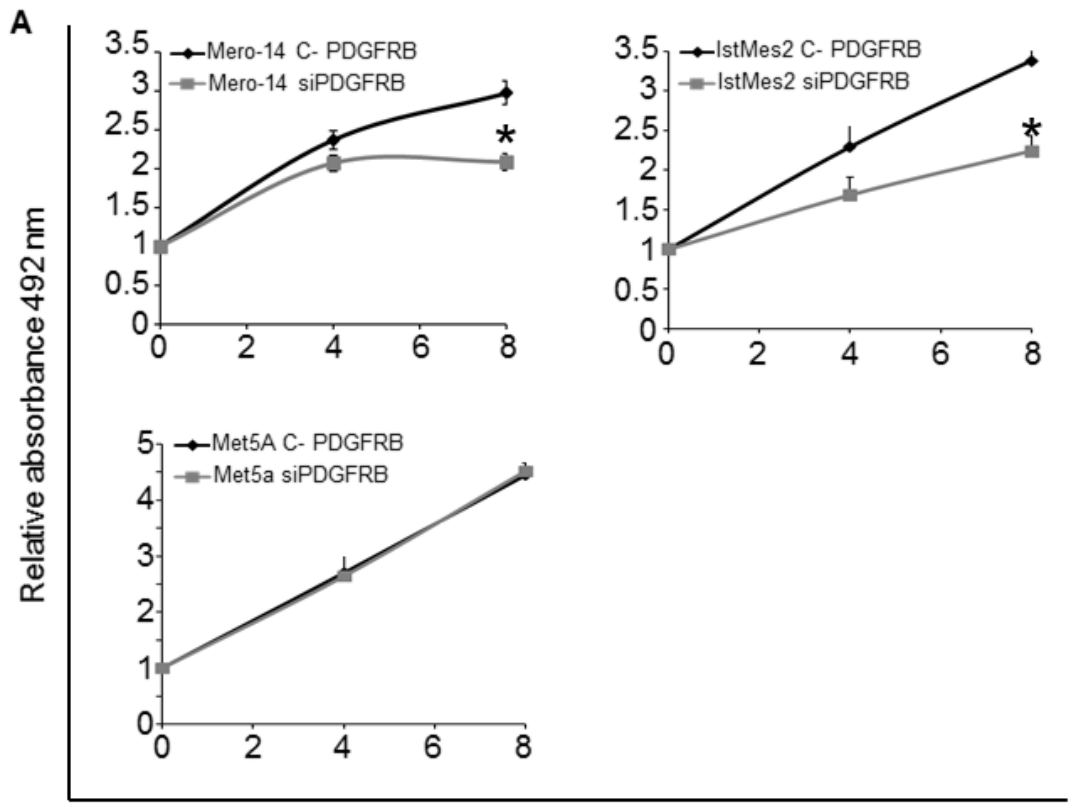

Days
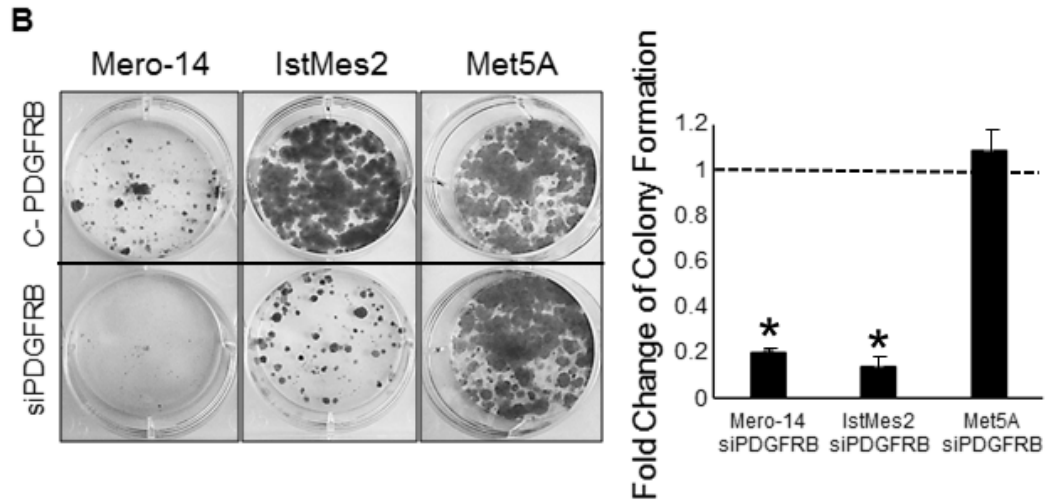

Figure 2: Role of PDGFRB in cellular growth. A. SRB proliferation assay in Mero-14, IstMes2 and Met5A cells treated with $50 \mathrm{nM}$ of the C-PDGFRB or siPDGFRB. Error bars represent SEM of three independent experiments, each performed in quadruplicate. B. Clonogenic assay: representative micrographs of colonies formed by C-PDGRB (top) and siPDGFRB (bottom) transfected Mero-14, IstMes2 and Met5A cell lines on the left and the corresponding histograms of each measurement on the right. Two different experiments were performed, each in triplicate. 
C-PDGFRB, at $72 \mathrm{~h}$ after PDGFRB depletion $(\mathrm{P}=0,019)$ (Figure 3B).

\section{PDGFRB silencing and anchorage-independent growth capacity}

Soft agar colony formation assay was performed to evaluate the malignant transformation potency on anchorage-independent growth of MPM cells with or without the administration of siPDGFRB. Colony formation on soft agar was observed in C-PDGFRB cells (Figure 4), whereas siPDGFRB treatment significantly decreased both size and number of soft agar colonies formed by Mero-14 and IstMes2 cells $(\mathrm{P}=0.006$ and $\mathrm{P}=0.007$ respectively). Mero- 25 cells were not able to form colonies on soft agar in both treated and control conditions, even after 28 days of culture (data not shown). No significant differences were detected in Met5A cell line. Hence the results of the soft agar assay confirmed that PDGFRB depletion decreased in vitro tumorigenic potential of MPM cells.

\section{PDGFRB drug inhibitors and cellular growth}

We next tested two PDGFRB inhibitors: crenolanib and imatinib. These small molecules are known to act by preventing PDGF-induced PDGFR autophosphorylation, and their effect on MPM cell lines was then compared. Similar to that found after PDGFRB gene-silencing, reductions of proliferative capabilities were observed, where the strongest activity of crenolanib was found on Mero-14 and IstMes2 cells, as reported in Figure 5A. The proliferation rate of Mero-14 cells suffered a reduction of about $25 \%$ (statistically significant, $\mathrm{P}=0.03$ ), whereas IstMes 2 cells reached a $40 \%$ reduction $(\mathrm{P}=0.04)$. Mero-25 cells seemed poorly sensitive to crenolanib, as the growth rate was only reduced slightly. No effect was found on Met5A cells. In this respect, the response of all cell lines was overlapping to that observed after siPDGFRB administration. Similar results were obtained

A

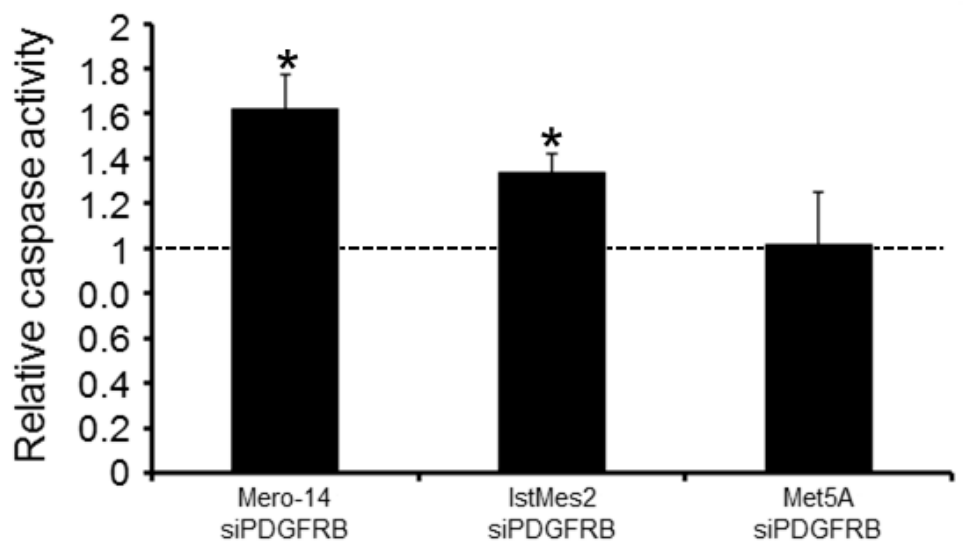

B
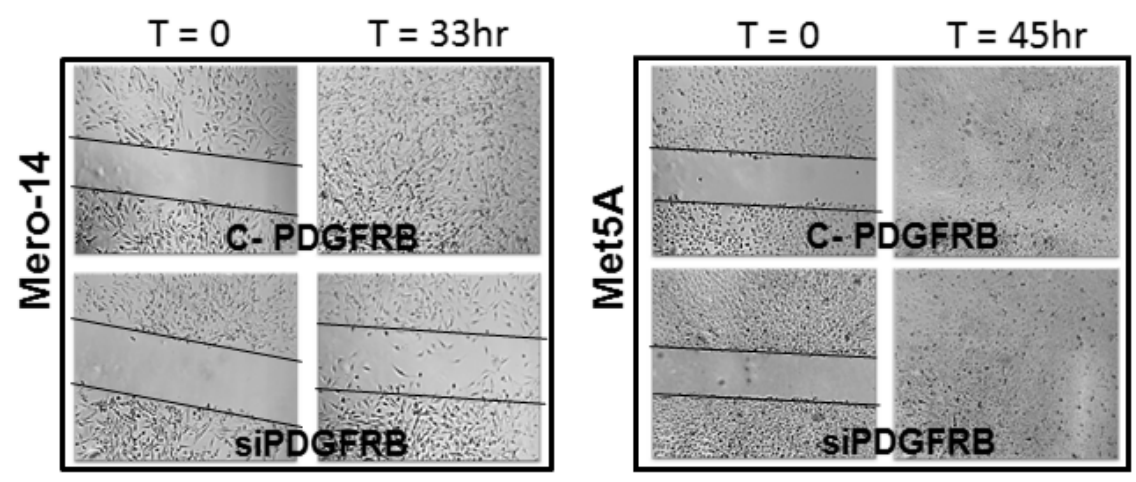

Figure 3: A. Role of PDGFRB in apoptosis. Caspase activity measured on Mero-14, IstMes2, and Met5A cells transfected with $50 \mathrm{nM}$ of C-PDGFRB (set to 1, black bar), or siPDGFRB. A marked increase in apoptosis is observed for Mero-14, IstMes 2 cells, but not for the non-MPM Met5A cells. Error bars represent SEM of three independent experiments, each performed in triplicate. B. Role of PDGFRB on cellular migration. Confluent monolayers of Mero-14 (left) and Met5A (right) cells transfected with $50 \mathrm{nM}$ of C-PDGFRB, or siPDFRB, respectively. Two different experiments were carried out, each performed in triplicate. Massive effect was observed in the wound-healing assay, following siRNA transfections, for Mero-14 cells. Met5A did not respond to siPDGFRB in the migration ability. 
after treatment with imatinib (Figure 5B), but with 25-fold higher doses. When an arbitrarily chosen and intermediate concentration of $8 \mu \mathrm{M}$ for both molecules was employed, as expected, the inhibitory effect of crenolanib was much stronger, whereas imatinib was almost ineffective $(\mathrm{P}=10$ ${ }^{4}$, data not shown).

Crenolanib (at $1 \mu \mathrm{M}$ ) and imatinib (at $25 \mu \mathrm{M}$ ) were both efficient in abolishing the colony formation capacity of Mero-14 $\left(\mathrm{P}_{\text {crenolanib }}=2 \times 10^{-3} ; \mathrm{P}_{\text {imatinib }}=6.3 \times 10^{-10}\right)$, IstMes2 $\left(\mathrm{P}_{\text {crenolanib }}=2.3 \times 10^{-3} ; \mathrm{P}_{\text {imatinib }}=1.48 \times 10^{-8}\right)$, and Mero-25 cells $\left(\mathrm{P}_{\text {crenolanib }}=0.02 ; \mathrm{P}_{\text {imatinib }}=2 \times 10^{-4}\right)$, without any statistically significant effect on the clonogenic survival of the Met5A cell line (Figure 6).

\section{PDGFRB drug inhibitors and cell cycle progression}

Similar to the observations made following treatment with siPDGFRB, the flow cytometry analysis showed that crenolanib induces an increase in the share of cells in sub- $\mathrm{G}_{1}$ for Mero-14 $\left(\mathrm{P}=2 \times 10^{-3}\right)$ and IstMes2 $(\mathrm{P}=0.04)$, a reduced share of cells in $\mathrm{G}_{0} / \mathrm{G}_{1}$ phase $(\mathrm{P}=1 \times 10$ ${ }^{3}$ for Mero- 14 cells, and $\mathrm{P}=0.05$ for IstMes 2 cells), and an accumulation in $\mathrm{G}_{2} / \mathrm{M}$ phase for IstMes 2 cells $(\mathrm{P}=0.04)$. In addition, an accumulation in $\mathrm{G}_{2} / \mathrm{M}$ phase was also observed for Mero- 25 cells $(\mathrm{P}=0.01)$. The treatment with imatinib affected the cell cycle progression with lower efficacy compared to crenolanib: a statistically significant accumulation $(\mathrm{P}=0.02)$ of cells in $\mathrm{G}_{2} / \mathrm{M}$ phase was found only for IstMes 2 cell line. Met5A did not experience significant changes in the cell cycle progression during the treatment with either of these drugs (Table S2, B-C).

\section{PDGFRB drug inhibitors and apoptosis}

The caspase 3 and 7 activities were assayed on the four cell lines, after $72 \mathrm{~h}$ of a crenolanib or imatinib continuous treatment. With crenolanib at $1 \mu \mathrm{M}$ (Figure 7A), Mero-14 and IstMes2 showed a strong and statistically significant increase of apoptosis $\left(+54 \%, \mathrm{P}=3.8 \times 10^{-3}\right.$, and $+100 \% \mathrm{P}=0.017$, respectively), in agreement with the share of sub- $\mathrm{G}_{1}$ cells observed with flow cytometry analysis. Mero-25 showed an increased apoptosis rate $(+34 \%)$, but this was not statistically significant $(\mathrm{P}=0.12)$. Met5A cells had increased apoptosis $(+20 \%)$, slightly statistically significant, and not confirmed with the share
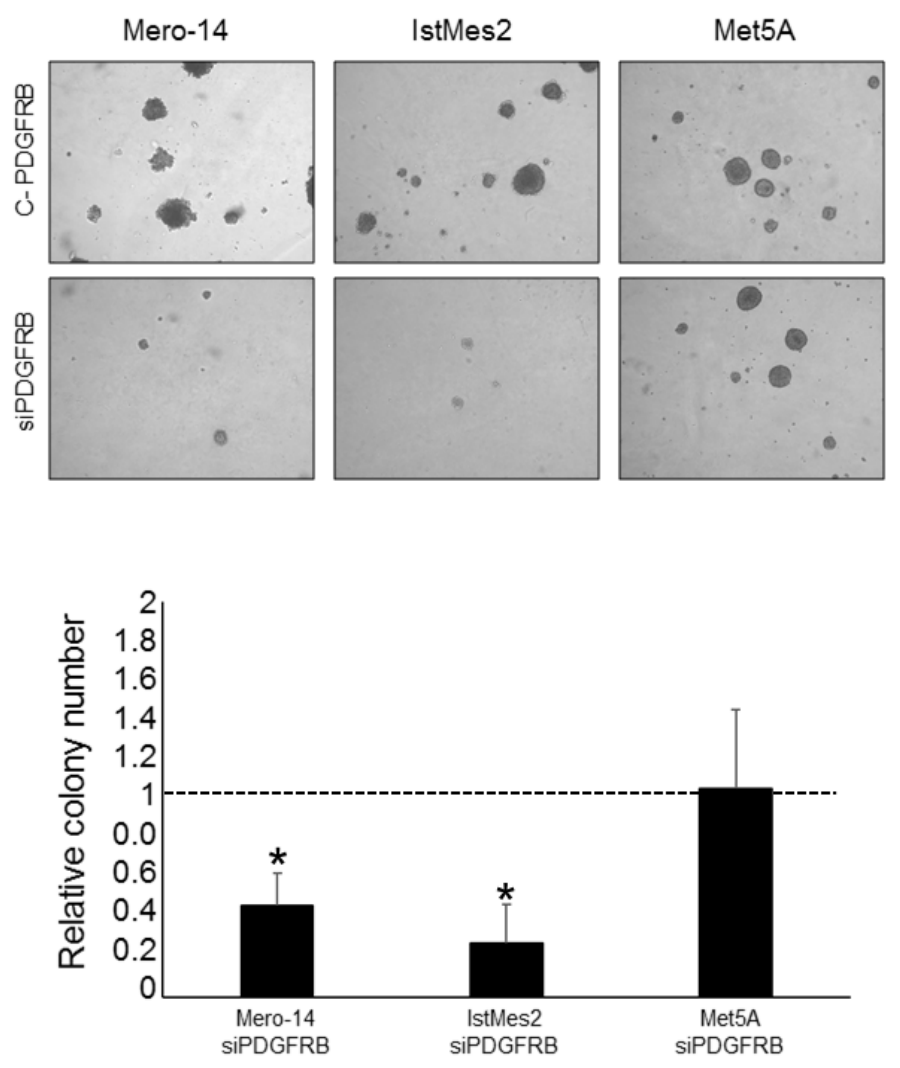

Figure 4: Role of PDGFRB in anchorage-independent growth capacity following siPDGFRB transfection. Representative images of soft agar colonies formed by C-PDGRB and siPDGFRB transfected Mero-14, IstMes2 and Met5A cell lines (top) and the corresponding histograms of each measurement (bottom). Error bars represent SEM of two independent experiments, each performed in triplicate. 
of sub- $\mathrm{G}_{1}$ cells observed with flow cytometry analysis. Imatinib treatment was not associated with increased apoptosis in any treated cell line.

\section{PDGFRB drug inhibitors and migration}

The cell migration ability of MPM cells was heavily compromised by treatment with crenolanib. Mero-14, IstMes2, and also Mero-25 treated cells showed a statistically significant difference in the closure of the scratch compared to the corresponding controls (Figure $7 \mathrm{~B} ; \mathrm{P}=0.04 ; 0.02 ; 7 \times 10^{-3}$ respectively). Imatinib treatment affected the migration capacity of Mero-25 cells with statistical significance $\left(\mathrm{P}=4 \times 10^{-3}\right)$, but not that of Mero14 and IstMes2 cells (Figure 7C), compared with their corresponding controls. Met5A cells were not able to close the scratch completely, and the difference with their corresponding control was not statistically significant.

\section{PDGFRB drug inhibitors and anchorage- independent growth capacity}

Crenolanib and imatinib treatment significantly decreased both size and number of soft agar colonies formed by Mero-14 $\left(\mathrm{P}_{\text {crenolanib }}=6 \times 10^{-5} ; \mathrm{P}_{\text {imatinib }}=4 \times 10^{-7}\right)$ and IstMes 2 cells $\left(\mathrm{P}_{\text {crenolanib }}=0.02 ; \mathrm{P}_{\text {imatinib }}=0.007\right)$ similar

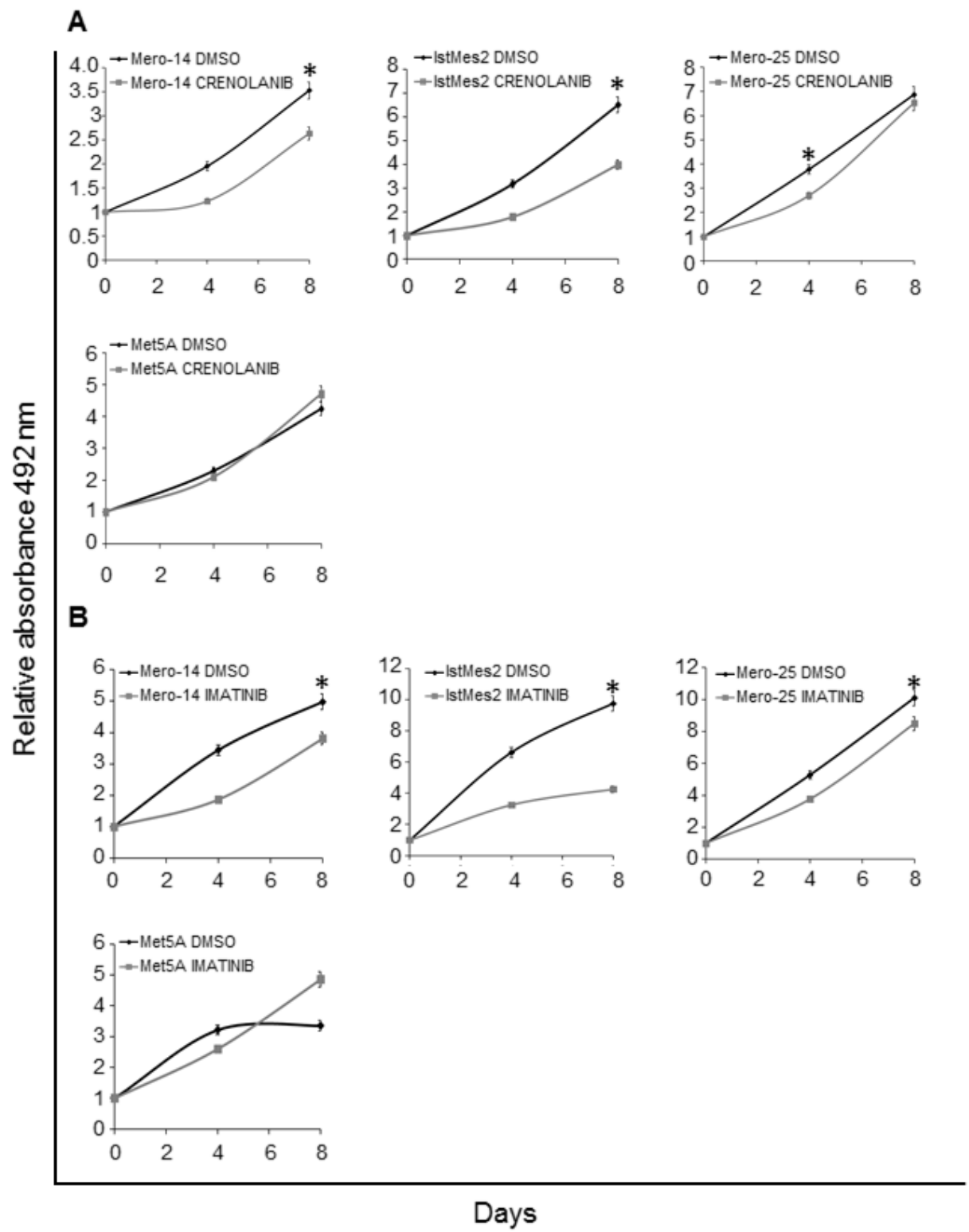

Figure 5: Role of PDGFRB in cellular growth, following treatment with chemotherapeutic drugs. A. Proliferation assay in Mero-14, IstMes2, Mero-25, and Met5A cells treated with DMSO or $1 \mu \mathrm{M}$ of crenolanib. Error bars represent SEM of three independent experiments, each performed in quadruplicate. B. Proliferation assay in Mero-14, IstMes2, Mero-25, and Met5A cells treated with DMSO or $25 \mu \mathrm{M}$ of imatinib. Error bars represent SEM of three independent experiments, each performed in quadruplicate. 
to that observed for siPDGFRB treatments. Mero-25 cells did not form colonies in any of the treatment conditions, nor in control (data not shown). Met5A did not show differences in soft agar colony formation capacity when treated with crenolanib compared to DMSO. These cells were more affected by imatinib treatment, forming smaller colonies than those of the control. However, the difference is not statistically significant (Figure 8).

\section{DISCUSSION}

In this work we studied somatic mutations within PDGFRB and the inhibition of PDGFRB on MPM. No activating gene mutations were detected and these results are in agreement with that found both in COSMIC (http:// cancer.sanger.ac.uk/cosmic) and TGCA databases. The former reports that, unlike $P D G F R A, P D G F R B$ gene is not frequently mutated at somatic level in cancer tissues (only 276 simple mutations in a total of 26.218 tested samples), the latter shows one missense mutation among 83 MPM specimens (1.2\%). On the other hand, MPM cells over-express PDGFRB mRNA [17] and 20-40\% of MPM specimens show immuno-reactivity for PDGFR beta-chain. Normal mesothelium usually does not show PDGFRB mRNA and protein expression [18]. Thus, it should be hypothesized that the tumor progression in MPM is driven by PDGFRB over-expression rather than its activating mutations. This suggests a completely different mechanism to that observed in GIST, where somatic mutations are frequently found within PDGFRA.

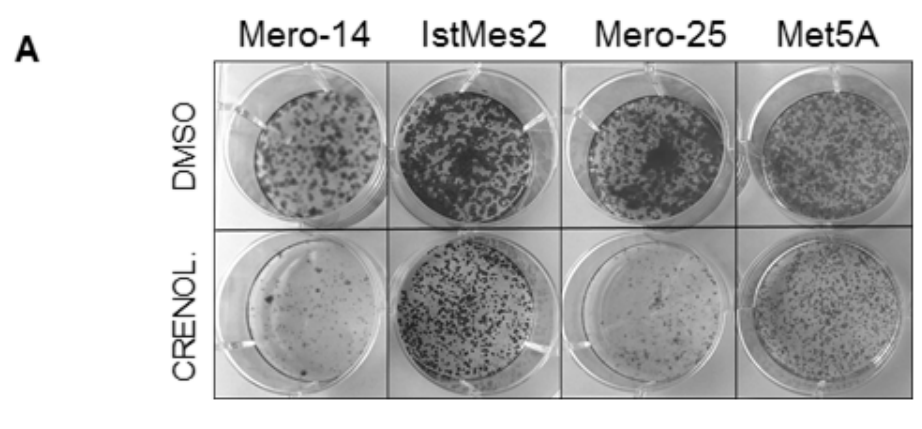

B

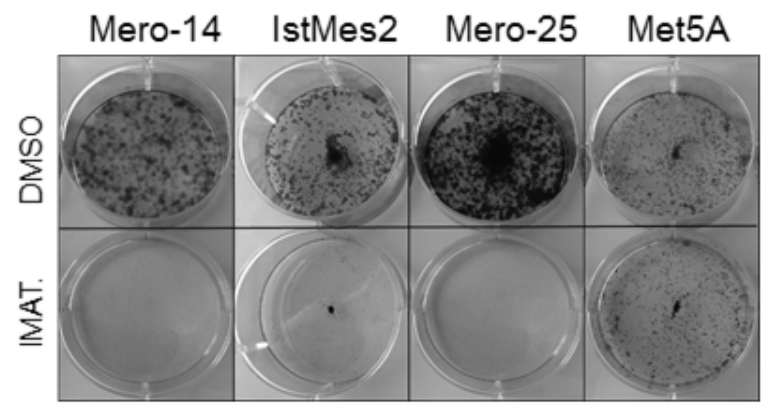

C

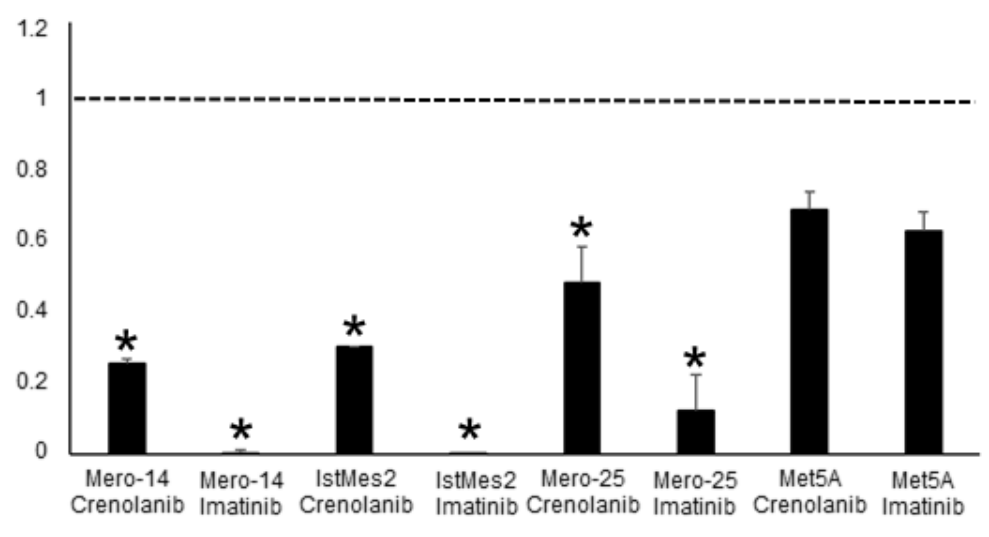

Figure 6: Role of PDGFRB in cellular growth, following treatment with crenolanib, and imatinib. A. Clonogenic assay: representative micrographs of colonies formed by Mero-14, IstMes2, Mero-25, and Met5A cell lines treated with DMSO (top) and crenolanib $(1 \mu \mathrm{M}$, bottom). B. Clonogenic assay: representative micrographs of colonies formed by Mero-14, IstMes2, Mero-25, and Met5A cell lines treated with DMSO (top) and imatinib ( $25 \mu \mathrm{M}$, bottom). C. Histograms corresponding to each measurement performed for crenolanib and imatinib. Two different experiments were performed, each in triplicate. 
A generalized overexpression of PDGFRB could be explained by a gain of the copy number of this gene. Preliminary observations at low resolution using fluorescence in situ hybridization suggested that less than $10 \%$ of MPM patients could show this phenomenon [19]. However, a search in TGCA portal showed that none of the 83 specimens had significant chromosomal gain/losses of the locus. Overall, these results suggest that the increased expression of PDGFRB should be ascribed to changes at transcriptional level and not to gene amplification.

It was also suggested that the cell growth stimulation triggered by PDGFRB could be caused by an autocrine loop, leading to the activation of tyrosine kinase receptors in MPM cells. The finding that ligands activating PDGFR populate the tumor stromal microenvironment seems to corroborate this hypothesis [20]. Thus, overall, these data suggest that PDGFRB is an important receptor involved in MPM progression. However, more research is warranted in order to provide further evidences. Thus, we analyzed the impact of PDGFRB gene silencing on MPM cell proliferation, cell cycle, apoptosis induction, and invasive behavior on a panel of cell lines, in order

A

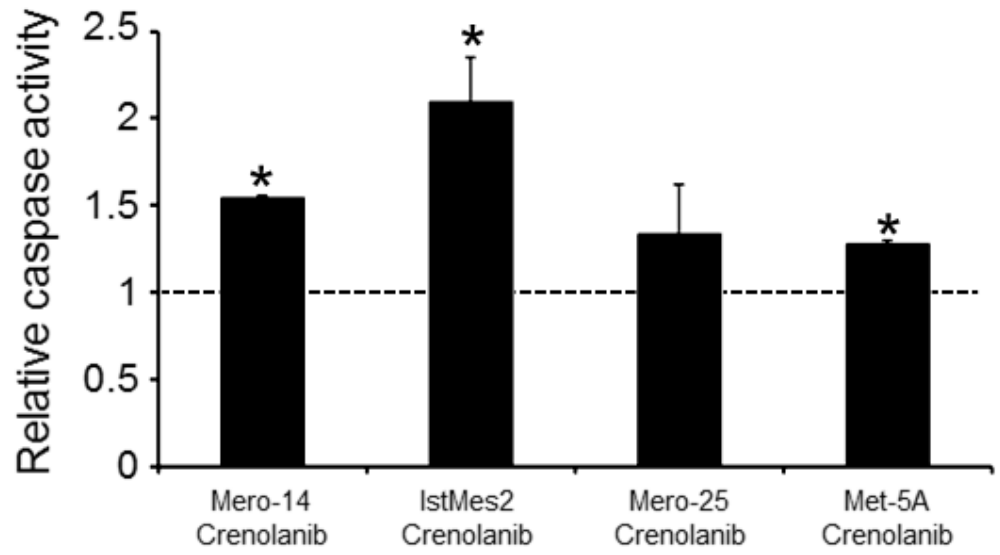

B

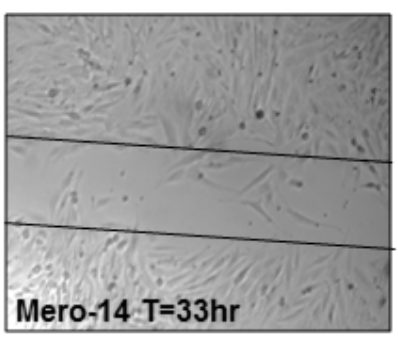

C

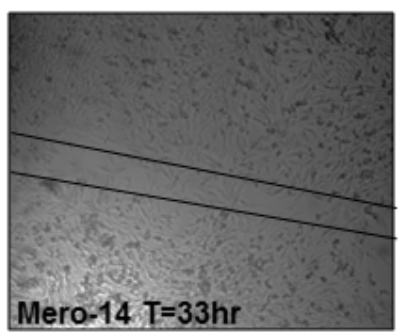

Crenolanib

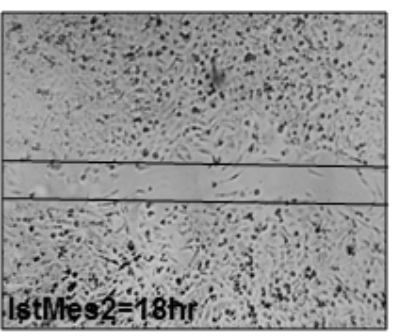

Imatinib

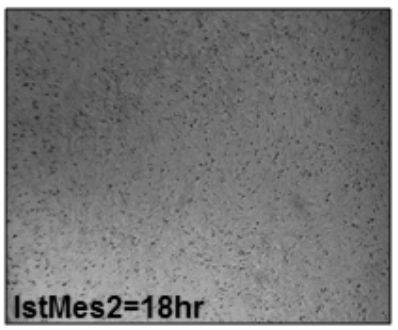

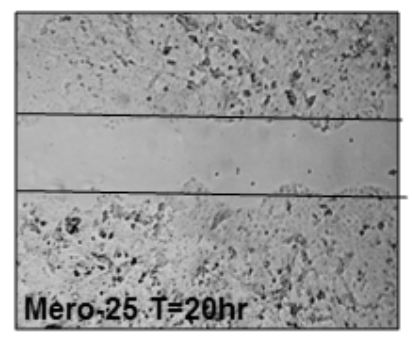

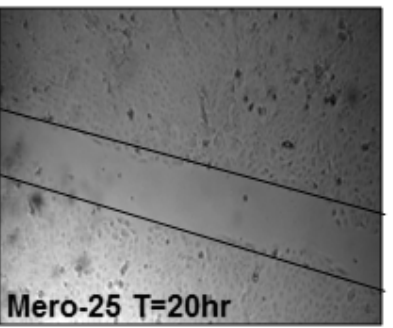

Figure 7: A. Role of PDGFRB in apoptosis, following treatment with crenolanib. Caspase activity measured on Mero-14, IstMes2, Mero25 , and Met5A cells treated with DMSO (set to 1, dotted black bar), or crenolanib $(1 \mu \mathrm{M})$. A marked increase in apoptosis is observed for Mero-14 and IstMes 2 cells. A slight induction of apoptosis is also reach by Mero-25 and Met5A cells, after treatment with crenolanib. Error bars represent SEM of three independent experiments, each performed in triplicate. B. Role of PDGFRB in cellular migration, following treatment with crenolanib, and imatinib. Confluent monolayers of Mero-14, IstMes2, and Mero-25 cells treated with $1 \mu \mathrm{M}$ of crenolanib (top), or $25 \mu \mathrm{M}$ of imatinib (bottom). Massive effect was observed in the wound-healing assay, following crenolanib treatment for Mero-14, IstMes2, and Mero-25 cells. Imatinib treatment impaired the migration ability of Mero-14 and Mero-25 cells, but not of IstMes2 cells. Two independent experiments were carried out, each performed in triplicate. 
to widen the cancer representativeness. The transient PDGFRB-silencing caused a decrease in the proliferation rate and a reduced colony formation capacity of Mero14 and IstMes 2 cell lines, as well as in anchorageindependent growth conditions. Moreover, PDGFRB depletion was associated with an increase in the share of cells in sub- $\mathrm{G}_{1}$ phase, as well as with an increased apoptotic rate of these cells. These data are in agreement with those observed by McGary, who demonstrated that the selective inhibition of the PDGFR tyrosine kinase through STI571 slowed PDGF-mediated growth and led to apoptosis of osteosarcoma cells in vitro [8]. In addition, Wang and co-workers showed that PDGFRB inhibition alone reduces spontaneous growth and metastasis in Ewing Sarcoma (EWS) [21]. In further work they demonstrated that PDGFRB depletion is fundamental in increasing the activity of TRAIL (tumor necrosis factorrelated apoptosis-inducing ligand) for the significant reduction of growth of EWS, as well as decreasing the number of incidences of spontaneous EWS pulmonary metastasis [22]. In a previous work, Zhang and co-workers showed that altered phosphorylation at the tyrosine kinase domain may potentially induce impaired signaling via the PDGF-B/PDGFR $\beta$ pathway, triggering a series of intracellular kinase cascades, such as those of Ras/Raf, MAPK, PI3K/AKT and FAK [23]. Their activation would then act as a proliferative stimuli and lead to the inhibition of apoptosis [24-26].

IstMes2 and Mero-14 cells underwent an accumulation in $\mathrm{G}_{2} / \mathrm{M}$ phase after siPDGFRB treatment.
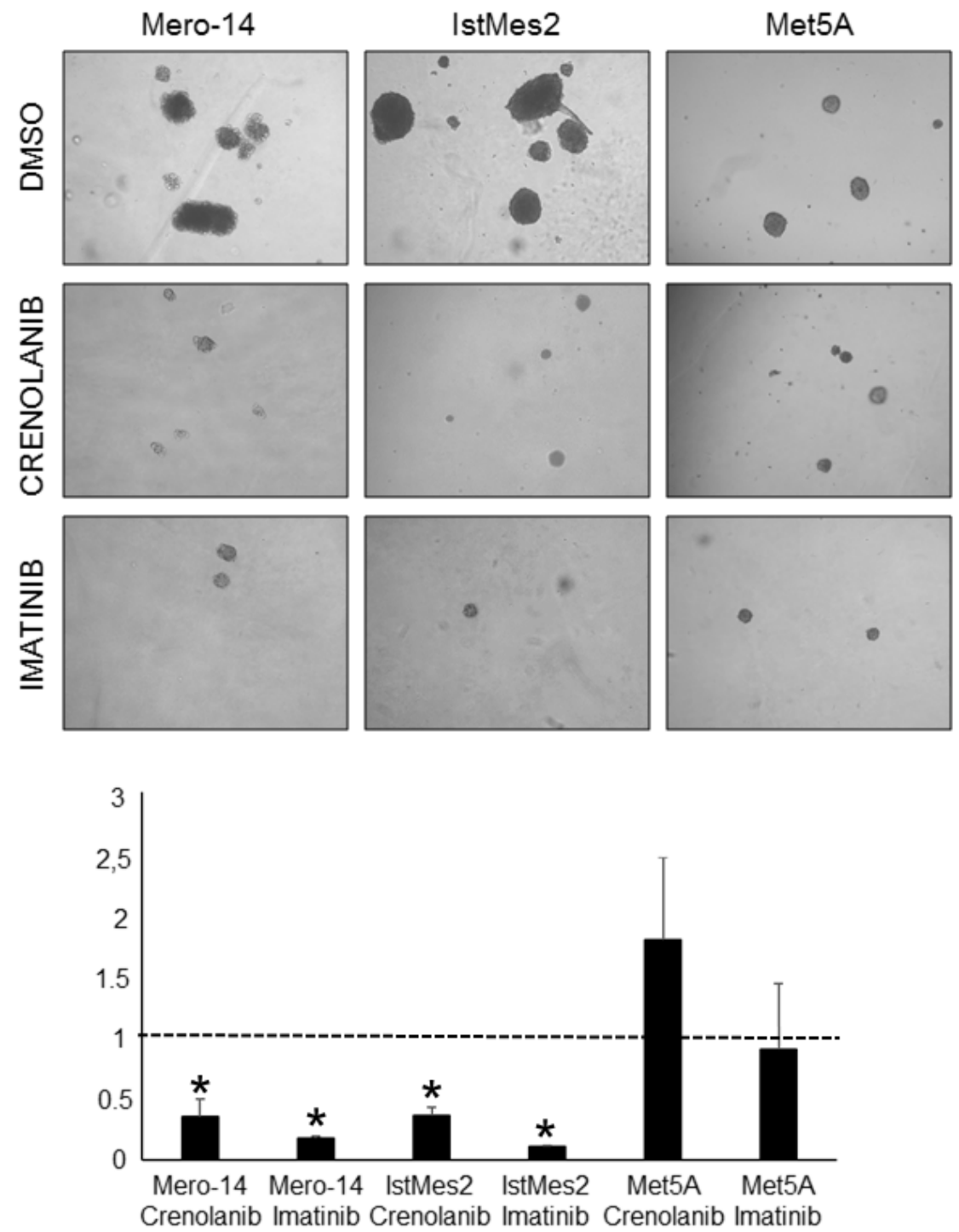

Figure 8: Role of PDGFRB in anchorage-independent growth capacity following drugs inhibitors treatments. Representative images of soft agar colonies formed by DMSO, crenolanib and imatinib treated Mero-14, IstMes2 and Met5A cell lines (top) and the corresponding histograms of each measurement (bottom). Error bars represent SEM of two independent experiments, each performed in triplicate. 
This data suggests that inhibition of PDGFRB could determine the $G_{2}$ checkpoint recovery arrest. Indeed, a role of PDGFRB in the $\mathrm{G}_{2}$ checkpoint was suggested in work by Sun and co-workers [27]. More recently, in support of this hypothesis, it has been shown that imatinib delayed recovery from checkpoint arrest and inhibited the subsequent $\mathrm{S}-\mathrm{G}_{2}-\mathrm{M}$ transition, through a persistent activation of ATR-Chk1 signaling, known to be fundamental for the maintenance of $G_{2}$ checkpoint arrest. For this reason, the authors suggested that imatinib may inhibit resumption of tumor proliferation after chemotherapy [28].

Loss of migration ability in the IstMes 2 cell line, following PDGFRB siRNA administration, was also observed. This data is in agreement with studies highlighting how PDGFRB activity is involved not only in cell growth, but also in the MPM chemotaxis. To support these results, experiments using UTI, a urinary trypsin inhibitor that neutralizes the activation of PDGFR $\beta$ cascade, showed that migration of MPM cells is inhibited [29]. Moreover, Abouantoun and co-workers showed PDGFRB tyrosine kinase activity is critical for migration and invasion of medulloblastoma cells, possibly by transactivating EGFR, and thus its depletion may represent an important therapeutic strategy for the treatment of this cancer [30].

Therefore, our results have shown that reverting PDGFRB over-expression can affect cell growth, migration and apoptosis in MPM cell lines. Interestingly, non-malignant cells (Met5A) did not seem to be affected by the $P D G F R B$ silencing, suggesting that this gene might be an effective therapeutic target. These evidences together with the fact that a plethora of PDGFRB inhibitors are currently employed in a series of clinical trials, prompted us to investigate whether the phenotypic effect obtained with transient transfection of MPM cell lines could be confirmed through the use of drug inhibitors such as crenolanib or imatinib.

The similar results observed between crenolanib and siPDGFRB confirmed that the effects induced by this drug could be largely mediated through PDGFRB inactivation (being crenolanib designed to be a specific PDGFR inhibitor). Interestingly, both crenolanib and imatinib were effective on Mero-25 cells, that did not respond well to gene silencing, likely due to the weak transfection efficiency found with this cell line. Alternatively, crenolanib and imatinib could inhibit other tyrosine kinase receptors activities inducing increased effects on -Mero25 cells. In fact, we are aware that the specificity of these inhibitors on PDGFRB is reduced as compared to that of gene silencing. This may explain the variable responses observed among the different MPM cell lines, also in relation to the different endogenous levels of PDGFRA and FLT3 expressed by Mero-14, IstMes2, and Mero-25 cells (Supplementary Figure 1). Indeed, crenolanib is a potent and selective inhibitor also of PDGFRA and FLT3 (the FMS-related tyrosine kinase 3), whereas imatinib is a tyrosine kinase inhibitor (TKI) targeting also BCR-ABL, KIT, and PDGFRA.

As regard imatinib, Bertino and co-workers [2], have reported that this drug has the ability to induce cytotoxicity and apoptosis selectively on PDGFRB positive MPM cells via blockade of receptor phosphorylation and interference with the Akt pathway. To our knowledge, crenolanib has never been tested in MPM. We compared the effect of both the inhibitors, clearly establishing the major efficacy of crenolanib on blocking the malignant phenotype of MPM cells. Indeed, crenolanib has been shown as more efficient than imatinb, even at lower doses, with a Ki about 30 times less than imatinib. Crenolanib is a potent class III receptor tyrosine kinase inhibitor including PDGFRB, with minimal toxicity, whose therapeutic efficacy has already been validated through clinical trials in GIST and human acute myeloid leukemia. Moreover, preclinical evidences showed benefit for lung cancer patients with deregulated PDGFR signaling [31].

Thus, our findings provided a rationale to explore further the efficacy of crenolanib in MPM patients, when characterized by an over-expression of PDGFRB, with promising results greater than those obtained with the use of imatinib. Indeed, previous clinical trials suggested that imatinib, as a single agent, has a limited efficacy in MPM patients [32,33]. The introduction of crenolanib may represent a robust strategy to improve the survival of MPM patients who present with PDGFRB positivity.

In conclusion, this study highlights the importance of the role played by PDGFRB in the MPM malignancy and has provided a rationale for its use as a potential therapeutic target. We also suggest that crenolanib could be an important therapeutic option for MPM patients, which warrants further investigation in order to explore its usefulness as a form of personalized therapy for this cancer type.

\section{MATERIALS AND METHODS}

\section{Tissue collection and DNA sequencing}

Ninety-six samples from formalin fixed and paraffin embedded tissues (FFPE) of MPM patients hospitalized and surgically resected for the tumor were enrolled for PDGFRB mutation screening. According to the Helsinki declaration, the local ethical committee approved the study. All tumor samples used in this study were selected and dissected by an experienced pathologist. Demographic information is reported in Table S3. FFPE sections were de-paraffined by submersion in xylene; the tissue was then incubated overnight at $56^{\circ} \mathrm{C}$ with Proteinase $\mathrm{K}$ (Qiagen, UK) to allow samples lysis and DNA was extracted using the Trizol reagent (Invitrogen, CA, USA) following the 
manufacturer's instructions. To obtain RNA free genomic DNA, an RNase A (Qiagen, UK) treatment was performed following the protocol instructions. The concentration and purity of the isolated DNA were measured using a NanoDrop ND-1000 Spectrophotometer (Thermo Fisher Scientific, DE, USA). Subsequently, the mutation screening was performed with automatic sequencing (Sanger reaction), according to the standard protocol. Specifically, the whole exons 12 and 18 of PDGFRB were PCR-amplified from genomic DNA using the specific primer pairs: Forward= tgtcctagacggacgaacet (Exon 12) and gaagggtctttcccacaat (Exon 18) Reverse= ccaacttgagtccccacact (Exon 12), and cacactggtcaggagggaat (Exon 18) and sequenced using PCR oligonucleotide as sequencing primer.

Copy number alterations data of 83 MPM patients were obtained from Cancer Genome Atlas (TCGA) consortium.

\section{Cell cultures}

The mesothelial non-MPM immortalized cell line (Met5A), was purchased from ATCC and grown in Medium 199 with HEPES (Life Technologies, Monza, Italy) supplemented with $10 \% \mathrm{FCS}, 3.3 \mathrm{nM}$ epidermal growth factor (EGF, Life Technologies, Monza, Italy), 400 $\mathrm{nM}$ hydrocortisone (Sigma Aldrich Corp. St Louis, MO, USA), and $870 \mathrm{nM}$ insulin (Life Technologies, Monza, Italy). Three mesothelioma cell lines (Mero-14, Mero25, and IstMes2), kindly donated by Istituto Tumori of Genova (Italy), were cultured in DMEM medium (Lonza, Basel, Switzerland), with $10 \%$ of FCS.

\section{PDGFRB inhibitors and PDGFRB silencing RNA oligonucleotide}

Imatinib (Cayman Chemical, Michigan, USA) and Crenolanib (Selleckman) were dissolved in DMSO to give a final concentration of $10 \mathrm{mM}$, and used at the previously established $\mathrm{IC}_{30}$ concentration, that is of $25 \mu \mathrm{M}$ and $1 \mu \mathrm{M}$ respectively. The following primary antibodies were used: primary mouse monoclonal anti-PDGFRB, anti-PDGFRA, and anti-FLT3 (Santa Cruz, TX, USA; $1: 300$ ) or mouse monoclonal anti- $\beta$-actin (Anti-Actin, Clone C4, Millipore, MA, USA; 1:5000). IgG-HRP Santa Cruz (1:5000) was used as secondary antibody. Different silencing-RNAs (siRNAs) were tested, and purchased from Qiagen (Qiagen, UK). Further experiments were performed by using a single specific siRNA for $P D G F R B$ (SI00605738, the so-called "siPDGFRB" now-on) and the "AllStars Negative Control siRNA" (SI03650318, used as non-targeting control - the so-called "C-PDGFRB" nowon). siRNA oligonucleotides were re-suspended in the provided buffer at a final stock concentration of $20 \mathrm{mM}$, and employed at $50 \mathrm{nM}$ in each experiments. HiPerfect transfection reagent was employed for siRNA trasfection (Qiagen, UK), as previously described [16].

\section{RNA isolation, Quantitative Real-Time PCR (RT- qPCR) and Western Blotting}

These three techniques were performed as previously described [16,34]. Densitometry results of western blot were analysed with Image J software (NIH, Bethesda, MD, USA). For quantitative analysis, the signal intensity of each band was normalized with $ß$-actin densitometry values. Each density was compared to the intensity of the reference cell line (Met5A) and all western blot analyses were replicated twice for the calculation of the average increase.

\section{Sulphorhodamine (SRB) assay}

Cells were seeded in 96-well plates at a density of 3 $\mathrm{X} 10^{3}$. The next day, (day 0 ), one plate was assessed. The remaining plates were tested at 2-day intervals for a total of 8 days. Cells were fixed with $100 \mu \mathrm{L}$ per well of icecold 40\% (vol/vol) TCA (Sigma Aldrich Corp. St Louis, MO, USA), and then stained with $0.4 \%$ SRB solution (Sigma Aldrich Corp. St Louis, MO, USA). After staining, unbound dye was removed by washing five times with $1 \%$ acetic acid solution and left to air dry. The bound SRB dye was then solubilized by adding unbuffered Tris-base solution, and plates were then read at OD $492 \mathrm{~nm}$, using a microplate reader.

\section{Determination of drugs' doses}

Sub-confluent cells in 96-well plates were exposed for $48 \mathrm{~h}$ to medium supplemented with $2 \% \mathrm{FBS}$, with or without crenolanib (in a range of concentrations from 20 $\mu \mathrm{M}$ to $0.3 \mu \mathrm{M}$ ) or imatinib (in the range from $200 \mu \mathrm{M}$ to $0.1 \mu \mathrm{M})$. The different concentration ranges have been chosen based on previous literature searches. Cell viability was assessed by SRB assay on 3 replicates at each concentration point to determine single drug lethal concentration values and their critical $\mathrm{IC}_{50}$ and $\mathrm{IC}_{30}$ values. Normalised cytotoxicity percentages were obtained from the formula: $\left(\mathrm{A}_{570}\right.$ mean values of extracts from treated samples/ $\mathrm{A}_{570}$ mean values of extracts from untreated control samples) X 100. Because the dose-response relationship was similar in all employed cell lines (data not shown for brevity), the unique dose of $1 \mu \mathrm{M}$ for crenolanib and $25 \mu \mathrm{M}$ for imatinib (corresponding to the $\mathrm{IC}_{30}$ for both of them) was used for all the assays. 


\section{Colony formation assays}

$3 \times 10^{3}$ cells were seeded in a 96-well plate and, after $24 \mathrm{~h}$, transfected with the correct concentration of siPDGFRB, or treated with PDGFRB inhibitors. After 24 $\mathrm{h}$ post treatment, cells were transferred in 6-well plates and incubated for a further 14 days. Following 14 days incubation, growth medium was removed and cells fixed and stained in $10 \%$ ethanol solution containing $0.1 \%$ crystal violet for $1 \mathrm{~h}$. Colonies were then counted and measured with Image J software.

\section{Flow cytometry (FACS)}

After siRNA transfection or drug treatments for $72 \mathrm{~h}, 10^{5}$ cells were collected, washed in phosphatebuffered saline (PBS), pelleted by centrifugation and fixed in $70 \%$ ethanol. Immediately prior to staining, cells were suspended in PBS containing $50 \mu \mathrm{g} / \mathrm{ml}$ of RNAse A (Qiagen, UK), and then, stained with propidium iodide (final concentration $100 \mu \mathrm{g} / \mathrm{ml}$ ) overnight at $4^{\circ} \mathrm{C}$. The percentage of cells in subG $G_{1}, G_{0} / G_{1}, S$ and $G_{2} / M$ phases were determined from 10.000 cells using the BD C6 ACCURI Software (Becton Dickinson). The experiments were carried out three independent times (triplicates).

\section{Caspase - GloH 3/7 assay}

Caspase-3/7 activation was measured using the Caspase-Glo 3/7 Luminescence Assay (Promega Corp. Madison, Wisc., USA) according to the manufacturer's instructions. In a 6-well plate $3 \times 10^{5}$ cells were incubated. The day after, the cells were treated with siRNAs or PDGFRB inhibitors, for $72 \mathrm{~h}$. Then, the cells were collected by trypsinization, and approximately $15 \times 10^{3}$ cells were transferred in a 96-well white plate. Caspase3/7-Glo reagent was added, and the samples were incubated at $37^{\circ} \mathrm{C}$ for $1 \mathrm{~h}$. The luminescence that is proportional to the caspase 3/7 activities was determined by luminometer (Tecan Sunrise, Austria GMBH).

\section{Wound-Healing Assay}

$25 \times 10^{3}$ cells were seeded in a 6-well plate and, after 24h, transfected with siRNAs or PDGFRB inhibitors for $72 \mathrm{~h}$. A linear scratch in the confluent cell monolayer was made with a sterile pipette tip after $39 \mathrm{~h}$ (time optimized following preliminary trials) following siRNA transfection. Then, cells were rinsed and incubated in full medium. Finally, cells were photographed at $72 \mathrm{~h}$ (i.e. $33 \mathrm{~h}$ following the scratch) with an optical microscope at $10 \mathrm{X}$ magnification connected to a computer. The migration was then evaluated on the images, and measured using Image J software.

\section{Soft agar assay for colony formation}

Base layer of soft agar was prepared by pouring $1 \mathrm{~mL}$ of $0.9 \%$ agar in MPM cells media in each well of 6-well plates and allowed to polymerize for few minutes. Top layer of soft agar was prepared using $0.45 \%$ agar in MPM cells media and cells from each treatment groups (C-PDGFRB vs siPDGFRB; DMSO vs crenolanib and imatinib) were mixed (10.000 cells in $1 \mathrm{~mL}$ soft agar solution) and plated over the base layer in each well. All the soft agar plates were allowed to solidify and then maintained at $37^{\circ} \mathrm{C}$ with a humidified atmosphere containing 5\% CO2. Colony formation of cells on soft agar was monitored by microscopic observation on daily basis. On Day 14, colonies were counted manually using microscope and representative images were taken.

\section{Statistical analyses}

The measurements of gene expression performed on cell lines, and the results obtained from the in vitro assays were statistically evaluated using a two-tailed Student's t-test. The effects of the combination of treatments (drugs $+/$ - siRNAs) were evaluated with a multifactor analysis of variance (MANOVA) model. The statistics were performed with the software Statgraphics Centurion XV (StatPoint, Inc.).

\section{ACKNOWLEDGMENTS}

The authors thank Cathy Richards (Department of surgery RCSI, Dublin) for her prompt editing of the English language. This work was supported by Ministero della Salute-Bando Ricerca Finalizzata 2009 (RF-20091529895) and by GIME (Gruppo Italiano Mesotelioma) onlus. There are no conflicts of interest with regard to this manuscript. The authors thank Prof. Antonio Lucacchini and Prof. Maria Rosa Mazzoni (Department of Pharmacy, University of Pisa) and Dr. Roberto Favoni (IRCCS A.O.U. San Martino-IST, Laboratory of Gene Transfer) for the donation of the cell lines.

\section{CONFLICT OF INTEREST}

None declared.

\section{REFERENCES}

1. Prins JB, Langerak AW, Dirks RP, Van der Linden-Van Beurden CA, De Laat PA, Bloemers HP, Versnel MA. Identification of regulatory sequences in the promoter of the PDGF B-chain gene in malignant mesothelioma cell lines. Biochim Biophys Acta. 1996; 1317:223-232.

2. Bertino P, Porta C, Barbone D, Germano S, Busacca 
S, Pinato S, Tassi G, Favoni R, Gaudino G, Mutti L. Preliminary data suggestive of a novel translational approach to mesothelioma treatment: imatinib mesylate with gemcitabine or pemetrexed. Thorax. 2007; 62:690695.

3. Hart CE, Forstrom JW, Kelly JD, Seifert RA, Smith RA, Ross R, Murray MJ, Bowen-Pope DF. Two classes of PDGF receptor recognize different isoforms of PDGF. Science. 1988; 240:1529-1531.

4. Heldin $\mathrm{CH}$, Bäckström G, Ostman A, Hammacher A, Rönnstrand L, Rubin K, Nistér M, Westermark B. Binding of different dimeric forms of PDGF to human fibroblasts: evidence for two separate receptor types. EMBO J. 1988; 7:1387-1393.

5. Claesson-Welsh L, Eriksson A, Morén A, Severinsson L, Ek B, Ostman A, Betsholtz C, Heldin CH. cDNA cloning and expression of a human platelet-derived growth factor (PDGF) receptor specific for B-chain-containing PDGF molecules. Mol Cell Biol. 1988; 8:3476-3486.

6. Seifert RA, Hart CE, Phillips PE, Forstrom JW, Ross R, Murray MJ, Bowen-Pope DF. Two different subunits associate to create isoform-specific platelet-derived growth factor receptors. J Biol Chem. 1989; 264:8771-8778.

7. Versnel MA, Claesson-Welsh L, Hammacher A, Bouts MJ, van der Kwast TH, Eriksson A, Willemsen R, Weima SM, Hoogsteden HC, Hagemeijer A, et al. Human malignant mesothelioma cell lines express PDGF beta-receptors whereas cultured normal mesothelial cells express predominantly PDGF alpha-receptors. Oncogene. 1991; 6:2005-2011.

8. McGary EC, Weber K, Mills L, Doucet M, Lewis V, Lev DC, Fidler IJ, Bar-Eli M. Inhibition of platelet-derived growth factor-mediated proliferation of osteosarcoma cells by the novel tyrosine kinase inhibitor STI571. Clin Cancer Res. 2002; 8:3584-3591.

9. Schiffer, C.A. Signal transduction inhibition: changing paradigms in cancer care. Semin Oncol. 2001; 28 (5 Suppl 17): 34-39.

10. Dorai T, Kobayashi H, Holland JF, Ohnuma T. Modulation of platelet-derived growth factor-beta mRNA expression and cell growth in a human mesothelioma cell line by a hammerhead ribozyme. Mol Pharmacol. 1994; 46:437-444.

11. Wehler TC, Frerichs K, Graf C, Drescher D, Schimanski K, Biesterfeld S, Berger MR, Kanzler S, Junginger T, Galle PR, Moehler M, Gockel I, Schimanski CC. PDGFRalpha/ beta expression correlates with the metastatic behavior of human colorectal cancer: a possible rationale for a molecular targeting strategy. Oncol Rep. 2008; 19:697-704.

12. Steller EJ, Raats DA, Koster J, Rutten B, Govaert KM, Emmink BL, Snoeren N, van Hooff SR, Holstege FC, Maas C, Borel Rinkes IH, Kranenburg O. PDGFRB promotes liver metastasis formation of mesenchymal-like colorectal tumor cells. Neoplasia. 2013; 15:204-217.

13. Seymour L, Bezwoda WR. Positive immunostaining for platelet derived growth factor (PDGF) is an adverse prognostic factor in patients with advanced breast cancer. Breast Cancer Res Treat. 1994; 32:229-233.

14. Maass T, Thieringer FR, Mann A, Longerich T, Schirmacher P, Strand D, Hansen T, Galle PR, Teufel A, Kanzler S. Liver specific overexpression of platelet-derived growth factor-B accelerates liver cancer development in chemically induced liver carcinogenesis. Int J Cancer. 2011; 128:1259-1268.

15. Hwang RF, Yokoi K, Bucana CD, Tsan R, Killion JJ, Evans DB, Fidler IJ. Inhibition of platelet-derived growth factor receptor phosphorylation by STI571 (Gleevec) reduces growth and metastasis of human pancreatic carcinoma in an orthotopic nude mouse model. Clin Cancer Res. 2003; 9:6534-6544.

16. Melaiu O, Melissari E, Mutti L, Bracci E, De Santi C, Iofrida C, Di Russo M, Cristaudo A4, Bonotti A, Cipollini M, Garritano SI, Foddis R, Lucchi M, Pellegrini S, Gemignani F, Landi S. Expression status of candidate genes in mesothelioma tissues and cell lines. Mutat Res. 2015, 771:6-12.

17. Langerak AW, De Laat PA, Van Der Linden-Van Beurden CA, Delahaye M, Van Der Kwast TH, Hoogsteden HC, Benner R, Versnel MA. Expression of platelet-derived growth factor (PDGF) and PDGF receptors in human malignant mesothelioma in vitro and in vivo. J Pathol. 1996; 178:151-160.

18. Ramael M, Buysse C, van den Bossche J, Segers K, van Marck E. Immunoreactivity for the beta chain of the platelet-derived growth factor receptor in malignant mesothelioma and non-neoplastic mesothelium. J Pathol. 1992; 167:1-4.

19. Tsao A, Harun N, Fujimoto J, Devito V, Lee JJ, Kuhn E, Mehran R, Rice D, Moran C, Ki Hong W, Shen L, Suraokar $\mathrm{M}$, Wistuba I. Elevated PDGFRB gene copy number gain (CNG) is prognostic for improved survival outcomes in resected malignant pleural mesothelioma. Ann Diagn Pathol. 2014; 18: 140-145.

20. Hermanson M, Funa K, Hartman M, Claesson-Welsh L, Heldin CH, Westermark B, Nistér M. Platelet-derived growth factor and its receptors in human glioma tissue: expression of messenger RNA and protein suggests the presence of autocrine and paracrine loops. Cancer Res. 1992; 52:3213-3219.

21. Wang YX, Mandal D, Wang S, Hughes D, Pollock RE, Lev D, Kleinerman E, Hayes-Jordan A. Inhibiting plateletderived growth factor beta reduces Ewing's sarcoma growth and metastasis in a novel orthotopic human xenograft model. In Vivo. 2009; 23:903-909.

22. Wang Y, Mandal D, Wang S, Kleinerman ES, Pollock RE, Lev D, Hayes-Jordan A. Platelet-derived growth factor receptor beta inhibition increases tumor necrosis factorrelated apoptosis-inducing ligand (TRAIL) sensitivity: imatinib and TRAIL dual therapy. Cancer. 2010; 116:38923902 .

23. Zhang J, Chen T, Mao Q, Lin J, Jia J, Li S, Xiong W, Lin Y, Liu Z, Liu X, Zhao H, Wang G, Zheng D, Qiu S, Ge J. 
PDGFR- $\beta$-activated ACK1-AKT signaling promotes glioma tumorigenesis. Int J Cancer. 2015, 136:1769-1780.

24. Kennedy SG, Wagner AJ, Conzen SD, Jordán J, Bellacosa A, Tsichlis PN, Hay N. The PI 3-kinase/Akt signaling pathway delivers an anti-apoptotic signal. Genes Dev. 1997; 11:701-713.

25. Zhang SX, Gozal D, Sachleben LR Jr, Rane M, Klein JB, Gozal E. Hypoxia induces an autocrine-paracrine survival pathway via platelet-derived growth factor (PDGF)-B/ PDGF-beta receptor/phosphatidylinositol 3-kinase/ Akt signaling in RN46A neuronal cells. FASEB J. 2003; 17:1709-1711.

26. Okada A, Yaguchi T, Kanno T, Gotoh A, Nakano T, Nishizaki T. PDGF-D/PDGF- $\beta \beta$ receptor-regulated chemotaxis of malignant mesothelioma cells. Cell Physiol Biochem. 2012; 29:241-250.

27. Sun Hq, Lin Km, Yin HL. Gelsolin modulates phospholipase $\mathrm{C}$ activity in vivo through phospholipid binding. J Cell Biol. 1997; 138:811-820.

28. Morii M, Fukumoto Y, Kubota S, Yamaguchi N, Nakayama Y, Yamaguchi N. Imatinib inhibits inactivation of the ATM/ ATR signaling pathway and recovery from adriamycin/ doxorubicin-induced DNA damage checkpoint arrest. Cell Biol Int. 2015; 39:923-932.

29. Yaguchi T, Muramoto M, Nakano T, Nishizaki T. Urinary trypsin inhibitor suppresses migration of malignant mesothelioma. Cancer Lett. 2010; 288:214-218.

30. Abouantoun TJ, MacDonald TJ. Imatinib blocks migration and invasion of medulloblastoma cells by concurrently inhibiting activation of platelet-derived growth factor receptor and transactivation of epidermal growth factor receptor. Mol Cancer Ther. 2009; 8:1137-1147.

31. Wang P, Song L, Ge H, Jin P, Jiang Y, Hu W, Geng N. Crenolanib, a PDGFR inhibitor, suppresses lung cancer cell proliferation and inhibits tumor growth in vivo. Onco Targets Ther. 2014; 7:1761-1768.

32. Mathy A, Baas P, Dalesio O, van Zandwijk N. Limited efficacy of imatinib mesylate in malignant mesothelioma: a phase II trial. Lung Cancer. 2005; 50:83-86.

33. Porta C, Mutti L, Tassi G. Negative results of an Italian Group for Mesothelioma (G.I.Me.) pilot study of singleagent imatinib mesylate in malignant pleural mesothelioma. Cancer Chemother Pharmacol. 2007; 59:149-150.

34. Melaiu O, Stebbing J, Lombardo Y, Bracci E, Uehara N, Bonotti A, Cristaudo A, Foddis R, Mutti L, Barale R, Gemignani F, Giamas G, Landi S. MSLN gene silencing has an anti-malignant effect on cell lines overexpressing mesothelin deriving from malignant pleural mesothelioma. PLoS One. 2014; 9:e85935. 